\title{
Analysis of Green Insurance Development and Product Innovation in China ${ }^{1}$
}

\begin{abstract}
Jingyu Liang
School of Finance, Guizhou University of Finance and Economics, Guiyang Guizhou 550025 , China

Abstract

Green insurance generally refers to Environmental Pollution Liability Insurance(EPLI) and has the functions of economic compensation and social management, which has attracted more and more attention in the field of environmental protection. China's EPLI has achieved rapid growth in the past few years, but its proportion in property insurance is at a low level and there is a great room for its development and improvement. China's EPLI products have a certain degree of innovation in guarantee amount, gradual pollution compensation and predicted environmental risk investigation, etc.. We can do further work in promoting the legal provisions of EPLI, and at the same time use more market measures to promote the development of EPLI.
\end{abstract}

\section{Keywords}

Environmental Pollution Liability insurance(EPLI); Environmental pollution; Innovation

\section{我国绿色保险发展及产品创新性分析}

\author{
梁景禹 \\ 贵州财经大学金融学院, 贵阳 550025, 中国
}

摘要：绿色保险一般指环境污染责任保险，目前我国已经处于环境压力高峰期，而绿色保险 具有经济补偿和社会管理的双重职能，在环境保护上发挥的作用正越来越受到重视，我国的 绿色保险最近几年获得快速发展, 但在财产保险中的占比处于较低水平, 还存在较大发展和 完善的空间，我国绿色保险产品在保障金额、渐进性污染赔付、事前环保风险排查等方面有 一定程度的创新。我们可以在推广绿色保险的法制规定上做进一步的工作，同时运用更多的 市场手段促进绿色保险的发展。

关键词：绿色保险；环境污染；创新性

${ }^{1}$ 本文受省科技厅软科学项目 黔科合体 R 字[2013]LKC2014 号资助 
改革开放以来, 特别是近 20 年, 既是我国经济飞速发展的时期, 也是 我国环境问题日益凸显的时期。环境 污染事故不仅是全球所面临的问题, 更是我国未来经济持续健康发展的主 要障碍之一。在面临解决环境污染事 故中, 绿色保险作为一个治理环境污 染有效的市场手段, 越来越受到重 视。绿色保险即环境污染责任保险, 是以市场手段抑制和转移企业环境污 染风险、保障污染受害者合法权益的 一种商业保险。

\section{1. 我国绿色保险的发展及特点}

绿色保险具有经济补偿和社会管 理的双重职能, 其发展在美国、英国和 德国等发达国家已进入成熟的阶段, 相比国外发达国家, 我国的绿色保险 起步较晚。上世纪 90 年代, 保险公司 即推出了我国初期的绿色保险产品, 但市场规模很小，中间一度停办，而 与此同时我国的环境污染问题逐渐加 重, 经过相关部门和企业的大力推 动, 我国的绿色保险自 2007 年以来进 入了较快的发展阶段, 到 2015 年底已 取得明显发展, 综合这些年的情况, 我国绿色保险的发展主要呈现了如下 特点:

\section{1. 由政府行业管理部门和地方政府 推动实施}

我国的绿色保险初期为我国保险 公司和环保部门联合推出。1991 年, 大连率先开展绿色保险业务, 随后吉 林、沈阳及长春等地也相继做为绿色 保险的试点经营地区。但规模较小, 到 90 年代中期已经基本处于停滞状 态。

进入 21 世纪, 国家的环境保护工 作开始考虑从主要运用行政手段保护 环境转变为综合运用法律、经济、技
术等多种手段解决环境问题, 保险机 制受到更大重视, 2007 年底, 环保部 与保监会联合发布了《关于环境污染 责任保险工作的指导意见》, 决定选 择部分环境危害大、最易发生污染事 故和损失容易确定的行业、企业和地 区, 率先开展绿色保险的试点工作。

2013 年 2 月, 在对五年的试点情 况进行总结基础上, 环保部、保监会 进一步发布相关政策文件，明确发展 绿色金融的目的, 就是要支持环境改 善、应对气候变化和资源高效利用等 具有环境效益的项目, 绿色保险成为 绿色金融体系重要组成部分。另外做 出了一个重大的政策的调整, 针对涉 及重金属、石化、化工等高环境风险 的企业和行业, 以强制模式推行绿色 保险。

2014 年 8 月, 国务院印发《国务 院关于加快发展现代保险服务业的若 干意见》, 提出把与公众利益关系密 切的环境污染等领域作为责任保险发 展重点, 2015 年《生态文明体制改革 总体方案》提出深化环境污染责任保 险试点, 各地环保和保险监管等部门 积极推进。2016 中国杭州 G20 峰会首 次将绿色金融 “中国方案” 纳入 G20 议程。在我国的绿色保险发展进程 中, 政府的推动力度不断加大, 成为 推动绿色保险发展的主要推动力。

\section{2. 绿色保险推广已取得一定成效}

2007 年底, 我国再次启动绿色保 险试点工作, 全国各地环保和保险部 门开始积极进行绿色保险的推进, 试 点也在更多省市和行业展开。

2008 年, 全国投保绿色保险的企 业 718 家, 保费收入 1200 多万元, 2009 年达到 1682 家, 保费收入增加 4300 多万元。2011 年, 全国共有 2167 家企业和 3314 艘船舶投保了绿色保 险, 各类型企业投保数量有较大的提 
高。到 2016 年, 绿色保险保费 2.84 亿元, 提供风险保障金 263.73 亿元。 全年投保环境污染责任险企业 1.44 万 家次,

经过 20 年的尝试和探索, 我国绿 色保险的发展环境已经有了一定改 善。从 2007 年至 2015 年第三季度, 投保绿色保险的企业已经超过 4.5 万 家次，保险公司提供的风险保障金累 计超过 1000 亿元。与保费相比，相当 于投保企业的风险保障能力扩大近 93 倍。国内各主要保险公司都加入了试 点工作。绿色保险在防范环境风险、 补偿污染受害者、推动环境保护事中 事后监管方面发挥了积极作用。

\section{3. 绿色保险和责任保险最近几年获得 较快速发展}

由于绿色保险保费并不算高，而 是记入责任保险中，因此除前述内容 数据外, 我们以财产保险公司责任保 险的保费增长, 来间接了解我国绿色 保险的增长情况。

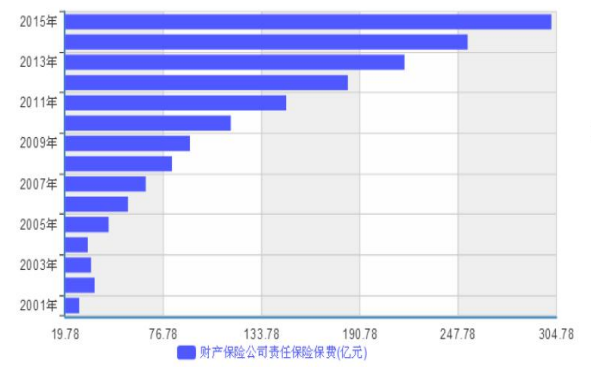

图 1 2001-2015 年财产保险公司责任保险保费增 长情况（数据来源：环保部公告）

图 1 所示, 我国绿色保险是 07 年 以后发展较快, 特别是 2012 年以后, 增长更进一步提速, 可以看出, 包含 绿色保险的责任保险在我国经济中的 作用开始逐渐显现。

\section{4. 绿色保险主要采取地方试点的方式 推进, 不同地区存在显著差别}

我国绿色保险主要采取试点推进 的方法, 在不同的地区分别开展, 因 此不同地区的绿色保险发展状况, 存 在显著区别, 开展试点的各个省市绿 色保险市场发展非常不平衡, 在 2011 年，江苏投保企业数量占全国总投保 企业数的 $53 \%$, 这一局面长期未得到改 变, 2015 年, 江苏投保企业数量占比 仍高达 59\%,。如图所示。

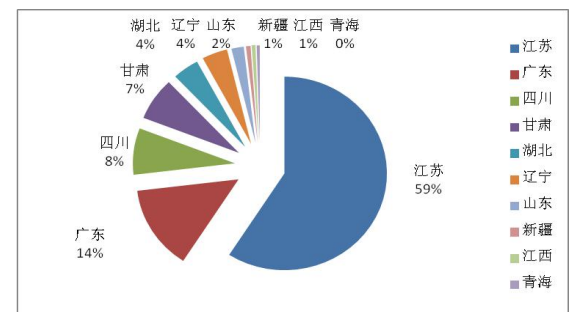

图 22015 年我国省市投保绿色保险企业数比例

各个省市绿色保险市场发展依然 非常不平衡, 并且这种不平衡与我国 生态环境的状况并不相匹配,一些地 区的绿色保险的投保状况不仅没有逐 年增长, 反倒逐年甚至大幅萎缩。此 外，在地域范围上并没有太大的进 展, 2012 年底, 全国有十多个省、自 治区、直辖市开展了相关试点, 2014 年全国投保绿色保险的企业覆盖了 22 个省份, 至 2015 年底, 全国还有许多 省市地区没有企业投保绿色保险产 品, 有绿色保险投保企业的省份相比 2014 年甚至有所萎缩。2015 年, 全国 投保绿色保险的企业分总数只有 4000 家企业, 相较 2014 年减少了 1000 家。 同期我国还面临的巨大环境压力, 两 相比较, 绿色保险的发展明显还跟不 上环境污染治理的需要。

\section{5. 绿色保险在财产保险中的占比处于 较低水平, 还存在较大空间}

虽然从保费收入来看, 我国绿色 保险保费收入已经逐渐接近 3 亿元, 但相对于我国 2.5 万亿的保费规模来 说几乎可以忽略不计; 与美国绿色保 
险保费每年多达 40 亿美元相比，我国 绿色保险保费收入更显得微不足道。

就以包含绿色保险的责任保险的 总保费收入来看，其在我国财产保险 公司保费收入中的占比也是极小的, 责任保险的赔付额度，在整个财产保 险的不额度中，同样占比也极小，如 图所示。

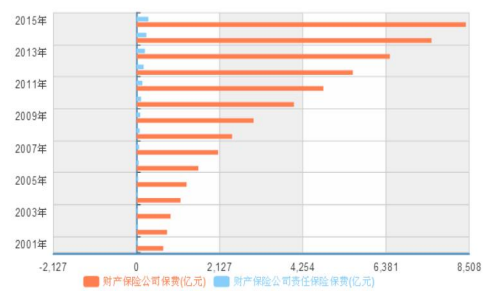

图 3 2001-2015 年责任保险与财产保险总保费对 比 (数据来源: 环保部公告)

至 2014 年底，各年投保绿色保险 的企业累积超过 2.5 万家次，保险公 司提供的风险保障金累计超过 600 亿 元，但同期我国规模以上企业已有 35 万余家，其中制造业企业就有 32 万多 家，以累积的投保次数数据来看，显 然绝大多数企业未投保绿色保险。

\section{2. 我国绿色保险产品创新性分析}

内资保险公司中，华泰保险公司 作为首家试水绿色保险的企业, 随后 江苏、湖北、湖南、河南、重庆、沈 阳、深圳、宁波、苏州等省市相继作 为试点地区开展绿色保险业务, 目前 主要保险公司陆续开展了绿色保险业 务。参与试点的保险产品从初期的 4 个发展到目前的 20 余个。

表 1 部分保险公司的绿色保险产品

\begin{tabular}{|c|c|}
\hline $\begin{array}{l}\text { 保险 } \\
\text { 公司 }\end{array}$ & 推出的的绿色保险产品 \\
\hline $\begin{array}{l}\text { 人保 } \\
\text { 财险 }\end{array}$ & $\begin{array}{l}\text { 1. 环境污染责任保险 } \\
\text { 2. 高新技术企业绿色保险 } \\
\text { 3. 内河船舶污染责任保险（部分试点省 } \\
\text { 市） }\end{array}$ \\
\hline
\end{tabular}

续表 1 部分保险公司的绿色保险产品

\begin{tabular}{|c|c|}
\hline $\begin{array}{l}\text { 保险 } \\
\text { 公司 }\end{array}$ & 推出的的绿色保险产品 \\
\hline $\begin{array}{l}\text { 平安 } \\
\text { 保险 }\end{array}$ & $\begin{array}{l}\text { 1. 河船舶污染责任保险 } \\
\text { 2. 环境污染责任保险 } \\
\text { 3. 平安绿色保险附加场所内清理费用保险 } \\
\text { 4. 平安高新技术企业绿色保险 } \\
\text { 5. 漏污染保险 } \\
\text { 6. 保企业责任保险 }\end{array}$ \\
\hline $\begin{array}{c}\text { 太平 } \\
\text { 洋财 } \\
\text { 险 }\end{array}$ & $\begin{array}{l}\text { 1. 舶污染责任保险 } \\
\text { 2. 危险化学品安全责任险（试点省市） }\end{array}$ \\
\hline $\begin{array}{l}\text { 华泰 } \\
\text { 保险 }\end{array}$ & $\begin{array}{l}\text { 1. 场所污染责任保险 } \\
\text { 2. 船舶污染责任保险、 } \\
\text { 3. 危险化学品企业安全生产责任保险 }\end{array}$ \\
\hline $\begin{array}{l}\text { 都邦 } \\
\text { 财险 }\end{array}$ & $\begin{array}{l}\text { 1. 污染法律责任 } \\
\text { 2. 意外渗漏及污染 }\end{array}$ \\
\hline $\begin{array}{l}\text { 华安 } \\
\text { 财险 }\end{array}$ & 环境污染责任保险 \\
\hline $\begin{array}{l}\text { 大地 } \\
\text { 保险 }\end{array}$ & 船舶油污责任保险 \\
\hline $\begin{array}{l}\text { 阳光 } \\
\text { 财险 }\end{array}$ & 环境污染责任保险 \\
\hline $\begin{array}{l}\text { 太平 } \\
\text { 财险 }\end{array}$ & $\begin{array}{l}\text { 1. 船舶污染责任保险 } \\
\text { 2. 船舶污染责任保险（适用于浙江地区） } \\
\text { 3. 高新技术企业绿色保险 } \\
\text { 4. 环境污染责任保险 } \\
\text { 5. 环境污染责任保险 (2014) } \\
\text { 6. 江苏地区环境污染责任保险 }\end{array}$ \\
\hline $\begin{array}{l}\text { 长安 } \\
\text { 责任 } \\
\text { 保险 }\end{array}$ & $\begin{array}{l}\text { 1. 环境污染责任险 } \\
\text { 2. 绿色装饰装修工程责任险 } \\
\text { 3. 水域船舶污染责任险 } \\
\text { 4. 环境污染责任险附加场所内清理费用保 } \\
\text { 险+附加精神损害赔偿责任保险 } \\
\text { 5. 房屋建筑工程质量责任险附加建筑材料 } \\
\text { 污染责任 } \\
\text { 6. 机动车附加油污污染责任险 }\end{array}$ \\
\hline $\begin{array}{l}\text { 安邦 } \\
\text { 财保 }\end{array}$ & $\begin{array}{l}\text { 1. 环境污染责任险 } \\
\text { 2. 山西省分公司绿色保险 } \\
\text { 3. 沿海船舶燃油污染责任险 }\end{array}$ \\
\hline $\begin{array}{l}\text { 永安 } \\
\text { 财险 }\end{array}$ & 内河船舶污染责任保险 \\
\hline $\begin{array}{l}\text { 安信 } \\
\text { 农险 }\end{array}$ & 危险化学品安全责任险 \\
\hline $\begin{array}{l}\text { 紫金 } \\
\text { 保险 }\end{array}$ & 紫金环境污染责任保险 \\
\hline $\begin{array}{l}\text { 美亚 } \\
\text { 财险 }\end{array}$ & 污染法律责任保险 \\
\hline $\begin{array}{l}\text { 瑞再 } \\
\text { 企商 } \\
\text { 保险 }\end{array}$ & $\begin{array}{l}\text { 可再生能源险（包含保险事故造成的非放 } \\
\text { 射性污染责任 ） }\end{array}$ \\
\hline
\end{tabular}

资料来源：根据各大保险公司门户网站整理 
从表 1 我们可以看出, 保险公司 都逐渐开展具有各自特色的绿色保险 产品。其保障范围大体包括：因污染 损害遭受损失进行赔偿的费用、必要 清污费用、合理施救费用、诉讼费、 调查取证费等相关必要费用。我国绿 色保险发展历程虽然相对短暂, 但在 保险产品上也做出了一定程度的创 新。归纳来看, 我国绿色保险产品的 创新性主要体现在以下方面:

\section{1. 为环境污染赔付提供较高的保障金 额}

华泰财险是第一家推出绿色保险 产品的保险公司, 于 2008 年 1 月推出 两款绿色保险产品：场所污染责任保 险和环境污染责任保险。其承保的典 型风险为: 与现行（或此前）生产活 动相关的土壤和水污染清理; 第三方 对于场所内排放的污染物造成的污染 索赔等。对于污染清理和第三方索赔 进行承保，提供了最高达 3 亿人民币 的保障额度。

\section{2. 为渐进性污染提供保障}

华泰财产保险股份有限公司推出 的场所污染责任保险产品适合各类企 业, 既可承保保险期限内发生的污染 事故, 也可以索赔时间为准, 考虑承 保以前发生的污染事故。除承保意外 突发污染外, 也可承保渐进性污染, 此外可扩展承保因污染事故导致企业 营业中断所致的损失。这为企业转移 环境污染责任风险提供了良好的选择 条件。

\section{3. 强调了对人的重视}

如安邦财产保险股份有限公司绿 色保险条款第四条: “发生意外事故 后，被保险人为了控制污染物的扩 散，尽量减少对第三者的损害，或为 了抢救第三者的生命、财产所发生的
合理必要的施救费用, 保险人负责赔 偿。”在产品条款中, 不只局限于对 财产和, 土地, 空气质量的保护, 还 特别强调了对生命的重视。

\section{4. 重视事前的环保风险排查}

江苏、陕西、辽宁等省在推进绿 色保险过程中, 已逐步融入风险评估 的内容, 将企业内在的生产设施、管 理措施等评价纳入指标, 作为费率的 调节系数。江苏省保险公司在事前第 三方评估机构进行风险测评，排查隐 患，保险期间也随时排查，这不仅有 效控制的企业的风险, 也侧面促进了 社会的防灾管理工作。

\section{5. 专门针对高科技企业进行扶持}

人保财险在试点地区推出了高新 技术企业绿色保险，已在湖北、辽 宁、宁波、江苏等地承保了多家家企 业, 太平财产保险有限公司也有高新 技术企业绿色保险产品。

\section{6. 支持精神损害索赔}

对大多数保险不予支持的精神索 赔, 华安保险约定, 如果第三者在保 险期间内首次向被保险人提出精神损 害索赔，对于被保险人依照中华人民 共和国法律（不包括港澳台地区法 律）应当承担的经济赔偿责任, 保险 人在约定的赔偿限额内负责赔偿。

\section{7. 在装修工程中推广绿色保险}

如长安责任保险的室内装修装饰 工程责任保险中涵盖环境污染责任条 款, 把绿色保险推广到建筑工程中, 推出了绿色装饰装修工程责任保险。 其第九条约定: 工程施工过程中, 因 突发意外事故导致污染损害, 保险人 在约定的赔偿限额内负责赔偿。 
环境污染事故的复杂性特征，也 导致保险公司面对很多赔偿中难以预 料的困难。保险公司对此采用了专门 的对应措施, 如平安集团推出的平安 环境污染责任保险在保单条款中，明 确规定把被保险人的故意行为、核辐 射、核污染、噪声、光、震动、电磁 辐射及其他放射性污染作为除外责 任, 把被保险人因从事污染导致的渐 进性污染作为免除责任。太平财产保 险有限公司江苏地区环境污染责任保 险条款中规定承保区域是指保险地址 及其边缘向外延伸一公里以内的范 围, 特意对污染地域范围进行限制, 以控制风险。

\section{3. 我国绿色保险及产品不足分析}

我国绿色保险产品的发展也存在 不足之处，比如保险产品多集中在基 于现有法律规定应当投保的渗漏污染 责任保险、船舶污染和油污污染保险 等, 而这些又基本上遵循我国法律要 求的而推出的险种, 对于法规中未要 求的水污染、噪声和振动责任保险、 核能和辐射污染、危险品运输、电磁 福射、能源类危害绿色保险涉足不 多; 绿色保险开展试点的对象也多是 法律和政府强制要求的化学品及石油 化工企业、污水处理厂、垃圾填埋场 和危险废物处置企业等。

要加快我国绿色保险的发展, 我 们可以在推广绿色保险的法制规定上 做进一步的工作，同时可以运用更多 的市场手段，鼓励保险公司推出适合 我国的新型绿色保险险种和创新型的 条款; 在强制模式、自愿模式和两者 结合模式上, 进一步探索选择适合我 国的绿色保险模式; 完善环境污染评 估手段方法, 降低保险公司绿色保险 的承保风险; 加强保险公司绿色保险 的专业性建设, 或者探索建立专业的 绿色保险公司; 应用新科技手段, 降
低绿色保险费率，提高企业自主购买 绿色保险的积极性等等。

随着时点为 2017 年 12 月 30 号第 二次全国环保污染普查工作的结束, 相信我们能够找出环境保护工作中的 着重点和更好的突破点, 在制度建设 和市场鼓励手段上有所创新, 我国的 绿色保险也会迎来一个新的蓬勃发展 局面, 为我国生态环境保护和经济持 续健康发展, 提供保险特有的保驾护 航作用。

\section{参考文献}

[1] 中国保险年鉴 2001-2016.

[2] 我国绿色保险体系的构建研究 [J]. 王珊珊. 现代营销(学苑 版). 2013(06).

[3] 绿色保险的共赢模式思考 [J]. 徐 波. 环境经济. 2013(09).

[4] 促进我国绿色保险发展的几点思考 [J]. 呼应. 时代金融. 2013(27).

[5] 绿色保险中的政府职责 [J]. 王 刚. 世界环境. 2011(04).

[6] 王向楠. 美国环境污染责任保险的 特点及借鉴意义 $[\mathrm{J}]$. 金融与经 济,2015,(09):55-57.

[7] 姜伟. 构建绿色发展模式投融资机 制 [J]. 经济研究导刊,2012,(26):118119.

[8] 梁雪珍. 我国绿色保险模式选择研 究[D].安徽财经大学, 2013 .

[9] 迈向环境可持续的未来: 中华人民 共和国国家环境分析 作者: 张庆 丰, (美) 克鲁克斯 著, 《迈向 环境可持续的未来》翻译组译出 版社: 中国财政经济出版社 出版时 间:2012 年 11 月. 